\title{
Performance and biochemical parameters of broiler chickens fed avocado (Persea americana) seed meal based diet
}

George, O. S., Allison, G. H. and Ekine, O. A.

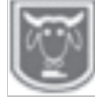

Abstract

Department of Animal Science, Faculty of Agriculture,

University of Port Harcourt,

PMB 5323, Port Harcourt, Rivers State, Nigeria.

Corresponding author: opuda.ekine@uniport.edu.ng.

An experiment was conducted to determine the effects of using Avocado seed meal (ASM) as a feed ingredient in broiler chickens feed. One hundred and twenty (120), one day-old cobb breed of broiler chickens were used. There were four (4) experimental diets with diet $1\left(T_{1}\right)$ serving as the control treatment with no inclusion of avocado seed meal (0.00). Diets 2,3 and 4 contained 0.50,1.00 and $1.50 \%$ inclusion of ASM, respectively. The experiment was arranged in a completely randomized design (CRD) with three (3) replicates per treatment. Each treatment had 30 birds with 10 birds per replicate. There were significant $(P<0.05)$ differences in final weight and average weight gain as $T_{2}$ with $0.50 \%$ inclusion of ASM was significantly $(P<0.05)$ higher for final weight (1338.33) and average weight gain (1290.33) than other treatments. While final weight (973.30) and average weight gain (925.33) in T4 with 1.50\% inclusion of ASM was significantly lower. There was no significant difference among initial weight, feed intake and FCR. Among all the biochemical parameters observed, only magnesium and urea were significantly different. Mg content was significantly higher in $T_{4}$ (32.33) and the least was observed in $T_{1}(1.80)$ while urea content was significantly higher in $T_{1}(1.80)$ and the least was observed in $T_{3}(1.03)$. From the performance parameters that was obtained, it was recommended that $0.50 \%$ of ASM should be used for broiler production in terms of body weight.

Keywords: Performance, biochemical parameters, body weight gain

\section{Introduction}

Livestock industry in Nigeria is faced with myriad of problems which have resulted to a gross shortage of meat and other animal products (Nworgu, 2002). Amongst the problems is population increase which has resulted to increased demand for meat and other animal products. Also high cost of feedstuffs relative to feed composition has scared some interested farmers from investing fully in poultry (Sese et al., 2013). The conventional protein feedstuffs continue to be scarce and expensive as they suffer from severe competition with human and other industrial users hence, the need to seek alternative plant protein sources for poultry feeds (Karsin et al., 2008). This suggests that alternative feed resources be identified and evaluated (Nworgu et al., 2017). In evaluating this unconventional feedstuff, their effects on health should be considered as well. One of the ways of providing more meat and animal products is the use of unconventional Feedstuffs like avocado seed. Avocado seed is a waste obtained from Avocado fruit (Perse aamericana) and has potential health benefits which include improving digestion, reducing risk of depression, cures diarrhoea or dysentery. Studies have shown that avocados are rich in macro nutrients like carbohydrate, vitamin and proteins (Whitney and Rolfes, 2005). It is used as a feed addictive as a result of its active constituent "polyphenols" with antioxidant and antimicrobial power which in some cases are better than synthetic antioxidants due to their toxicity when in excess (Dabas et al., 2013). However, some researchers have examined the impact of Avocado seed on muscle composition and oxidative stability during chilled storage of finishing 
pigs (Henry et al., 2015). This study was therefore designed to assess the Performance and biochemical parameters of broiler chickens fed avocado (Persea americana) seed meal based diet.

\section{Materials and methods}

The experiment was carried out at the poultry unit of the University of PortHarcourt Research and Demonstration farm, Choba campus, off East West Road, Choba, Port Harcourt, Rivers State, Niger Delta region, Nigeria and lies within latitude $4.89437^{\circ} \mathrm{N}$, longitude $6.91053^{\circ} \mathrm{E}$ and $16 \mathrm{~m}$ altitude, with an annual average Temperature of $28^{\circ} \mathrm{c}\left(82.40^{\circ} \mathrm{f}\right)$. The experiment lasted for eight (8) weeks. A total number of one hundred and twenty (120), one day-old broiler birds of the Cobbs breed were used for the experiment which lasted 8 weeks (56) days. The avocado seeds were procured from fruit sellers in PortHarcourt, Rivers State. The fresh avocado seeds were washed and sliced into smaller particles for effective drying. The sliced avocado seeds were thereafter

Table 1: Experimental composition of broiler starter diet

\begin{tabular}{lllll}
\hline Ingredients & T1 (0\%) & T2 (0.5\%) & T3 (1.0\%) & T4 (1.5\%) \\
\hline Yellow maize & 46.00 & 45.50 & 45.00 & 44.50 \\
PKC & 7.00 & 7.00 & 7.00 & 7.00 \\
Soyabean meal & 15.50 & 15.50 & 15.50 & 15.50 \\
Groundnut cake & 13.00 & 13.00 & 13.00 & 13.00 \\
Fish meal & 7.25 & 7.25 & 7.25 & 7.25 \\
Wheat bran & 4.50 & 4.50 & 4.50 & 4.50 \\
Bone meal & 3.00 & 3.00 & 3.00 & 3.00 \\
Methionine & 0.50 & 0.50 & 0.50 & 0.50 \\
Lysine & 0.50 & 0.50 & 0.50 & 0.50 \\
Vitamin/mineral & 2.50 & 2.50 & 2.50 & 2.50 \\
Salt & 0.25 & 0.25 & 0.25 & 0.25 \\
Avocado seed meal (ASM) & 0.00 & 0.50 & 1.00 & 1.50 \\
Total & $\mathbf{1 0 0}$ & $\mathbf{1 0 0}$ & $\mathbf{1 0 0}$ & $\mathbf{1 0 0}$ \\
Calculated analysis (\%) & & & & \\
Dry matter & 90.94 & 90.75 & 90.76 & 90.75 \\
Crude protein & 18.38 & 17.50 & 18.38 & 16.63 \\
ME (Kcal/kg) & 2950 & 3000 & 3010 & 2990 \\
\hline
\end{tabular}

Table 2: Experimental composition of broilerfinisher diet

\begin{tabular}{lllll}
\hline Ingredients & T1 (0\%) & T2 $(\mathbf{0 . 5} \%)$ & T3 $\mathbf{( 1 . 0 \% )}$ & T4 (1.5\%) \\
\hline Yellow maize & 47.50 & 47.00 & 46.50 & 46.00 \\
PKC & 8.50 & 8.50 & 8.50 & 8.50 \\
Soyabean meal & 14.25 & 14.25 & 14.25 & 14.25 \\
Groundnut cake & 11.00 & 11.00 & 11.00 & 11.00 \\
Fish meal & 6.50 & 6.50 & 6.50 & 6.50 \\
Wheat bran & 5.50 & 5.50 & 5.50 & 5.50 \\
Bone meal & 3.00 & 3.00 & 3.00 & 3.00 \\
Methionine & 0.50 & 0.50 & 0.50 & 0.50 \\
Lysine & 0.50 & 0.50 & 0.50 & 0.50 \\
Vitamin/mineral & 2.50 & 2.50 & 2.50 & 2.50 \\
Salt & 0.25 & 0.25 & 0.25 & 0.25 \\
Avocado seed meal (ASM) & 0.00 & 0.50 & 1.00 & 1.50 \\
Total & $\mathbf{1 0 0}$ & $\mathbf{1 0 0}$ & $\mathbf{1 0 0}$ & $\mathbf{1 0 0}$ \\
Calculated analysis (\%) & & & & \\
\hline Dry matter & 90.70 & 90.72 & 90.75 & 90.70 \\
Crude protein & 18.38 & 17.00 & 16.21 & 15.75 \\
ME (Kcal/kg) & 3020 & 3100 & 3078 & 3050 \\
\hline
\end{tabular}




\section{George, Allison and Ekine}

sundried for seven (7) days (6 hours daily) in an open ventilated space away from sunlight to reduce the anti-nutritional factors and moisture content in the seeds. The seeds were milled and incorporated into a formulated diet at $0,0.50,1.00$ and $1.50 \%$ for both starter and finisher phases (Table 1).

The broiler chicks were raised intensively in a deep litter poultry housing system. The chicks birds were subjected to same preexperimental management conditions for the first two weeks, during this period, they were administered with antibiotic and vaccines. They were individually weighed and allotted to four (4) different experimental treatments of three (3) replicates for each treatment and ten (10) birds per replicates in a completely randomized design (CRD). Four (4) experimental diets were formulated in which dried and graded avocado seed was added at an inclusion level of 0.00 (control), $0.50,1.00$ and $1.50 \%$ for $\mathrm{T}_{1}, \mathrm{~T}_{2}, \mathrm{~T}_{3}$ and $\mathrm{T}_{4}$ respectively. The experimental diets and clean drinking water were provided $\mathrm{ad}$ libitum throughout the experimental period of eight (8) weeks. Body weight gain was recorded on weekly basis (Saturdays). The feed intake was determined by weighing the quantity of feed given to the birds on daily basis and the left over using a gram sensitive scale. Feed conversion ratio was calculated in relation to the body weight gained and feed consumed. Blood samples were collected from the vein wing of three (3) different birds from each replicates (36 birds in total) with a three (3) $\mathrm{ml}$ disposable syringe and directly transferred a labelled and sterilized dry tube that does not contain Ethylene Diamin Tetra Acetic Acid (EDTA) which serves as anticoagulant and taken to laboratory for biochemical analysis which includes Aspatate aminotransferase (AST), Alkaline phosphate (ALP), Alanin aminotransferase (ALT), Total protein (T.P), Total blood (T.B), Liquid blood (L.B), sodium (Na), Magnesium (Mg), Potassium (K) and Urea. The obtained data were analyzed using one-way Analysis of Variance (ANOVA). Where significant treatment effect was detected, means were separated using Duncan's multiple range test (DMRT) using the Statistical Package for Social Sciences (SPSS) software.

\section{Results and discussion Performance parameters}

The feed intake, average body weight gain, final body weight and feed conversion ratio as influenced by dietary inclusion levels of avocado seed meal in broiler feed is presented in Table 3. Final weight and average weight gain revealed significant $(\mathrm{P}>0.05)$ differences among treatment groups with treatment2having highest final weight and average weight gain of 1338.33 and 1290.33 , respectively while treatment 4hadthe least (973.30 and 925.33) respectively. There was no significant difference in feed conversion ratio and feed intake. In Table 3 there was significant ( $P$ $<0.05)$ difference in final weight and average weight gain. This could be as a result of the anti-nutritional factors present in the avocado seed meal. Abeke (2005) reported that anti-nutritional factors exert negative influences on growth and feed utilization resulting in poor performance. The improvement in final weight and weight gain in chickens on T2 could also be as a result of the lower fibre content in the diet. Van Ryssen et al. (2013) reported that growth and feed utilization decreases with increase in fibre content in chicken diet. Also, Longe and Adekoya (1988) reported that feed ingredients high in fibre have been proved to affect physical texture of rations and decrease feed intake of birds. It was observed that as avocado seed meal concentration increases, the final weight decreases. This observation corresponds to report by Alikwe et al. (2013) that as the concentration of ACLM increased, there was a decrease in final live and average weight gain. There was no significant difference in feed intake, though relatively higher feed intake was observed in 


\section{Performance and biochemical parameters of broiler chickens fed avocado (Persea americana)}

treatment 3 while the least was observed in treatment 4 . The difference in feed intake could be as a result of dietary components of the feeds where the crude fibre content decreased with an increase in inclusion level of ASM (Van Ryssen et al., 2013). The author concluded that increase in fibre content in poultry diets reduces feed intake. There was no significant difference in feed conversion ratio of chickens fed avocado based diets. Relatively higher conversion was observed in treatment 3(1.90) while the least was observed in treatment 2 (1.60). This observation supports Sarangi et al. (2016) who reported no significant difference in the feed conversion ratio of broiler chicken during 0-6 weeks of age.

Table 3: Effects of avocado seed meal on performance parameters of broiler chickens

\begin{tabular}{lllll}
\hline Performance & \multicolumn{1}{c}{$\mathrm{T}_{1}(0.00 \%)$} & \multicolumn{1}{c}{$\mathrm{T}_{2}(0.50 \%)$} & \multicolumn{1}{c}{$\mathrm{T}_{3}(1.00 \%)$} & \multicolumn{1}{c}{$\mathrm{T}_{4}(1.50 \%)$} \\
\hline Initial weight & $48.03 \pm 00$ & $48.02 \pm 0.00$ & $48.00 \pm 0.00$ & $48.01 \pm 0.00$ \\
Final weight & $1316.70 \pm 0.00^{\mathrm{b}}$ & $1338.33 \pm 0.00^{\mathrm{a}}$ & $1166.67 \pm 0.00^{\mathrm{c}}$ & $973.30 \pm 0.00^{\mathrm{d}}$ \\
Average weight gain & $1268.70 \pm 0.00^{\mathrm{b}}$ & $1290.33 \pm 0.00^{\mathrm{a}}$ & $1118.67 \pm 0.00^{\mathrm{c}}$ & $925.33 \pm 0.00^{\mathrm{d}}$ \\
Average feed intake & $478.31 \pm 107.85$ & $473.53 \pm 106.25$ & $479.69 \pm 104.21$ & $473.31 \pm 106.52$ \\
Feed conversion ratio & $1.61 \pm 18$ & $1.60 \pm 17$ & $1.90 \pm 26$ & $1.86 \pm 25$ \\
\hline
\end{tabular}

a,b,c means in the same row with different superscripts varies significantly $(\mathrm{P}<0.05)$.

Effects of avocado seed meal on biochemical parameters of broiler chickens

Table 4 shows biochemical parameters of broiler chickens fed ASM. Among all biochemical parameters monitored, Magnesium (mg) and Urea were the only significant metabolites as $\mathrm{Mg}$ in treatment4 (32.33) was the highest while the least was observed in treatment 1 (24.67). Also, urea activities were highest in treatment 2 (1.80) and lowest in treatment 3 (1.03). Though not significant, the inclusion of avocado seed meal in the diet revealed a progressive increase in Total protein (T.P), Sodium $(\mathrm{Na})$, and potassium $(\mathrm{K})$ with increasing $\%$ of avocado seed meal along the treatment groups. The observed increase may be because avocado seed is rich in micro and macro nutrients like protein, vitamins, carbohydrates and minerals (Whitney et al., 2005). There were no significant differences in the activities of AST, ALT and ALP as the levels of avocados seed meal increased. These enzymes located in the liver, muscles or bones aid chemical activities within the organs in question. Reduced activities of the enzymes would adversely affect the organs or tissues were they are found. There was significant $(\mathrm{P}<0.05)$ difference between magnesium $(\mathrm{Mg})$ in the various treatments were T4is significantly higher (32.33) and $\mathrm{T} 1$ is significantly lower (24.67), but statistically, there is no difference between $\mathrm{T}_{3}$ and $\mathrm{T} 4$ (31.67) and 32.33), respectively. Similarly, there was significant $(\mathrm{P}<0.05)$ difference in urea among the four (4) treatments, were T1 is significantly higher (1.80) while T3 is significantly lower (1.03). The total protein and Urea content in T4 collaborates with earlier findings (Iyayi et al., 1998 and Esonu et al., 2001) that serum urea and T.P content depends on both the quantity and quality of the protein supplied in the diet. The increase in serum urea implies an increase in rate of deamination in the liver and this corresponds with the findings of Obun et al. (2013) that had similar observation. 
George, Allison and Ekine

Table 4: Effects of avocado seed meal on biochemical parameters of broiler chickens

\begin{tabular}{lllll}
\hline parameters & $\mathbf{T}_{\mathbf{1}(\mathbf{0 . 0 0} \%)}$ & $\mathbf{T}_{\mathbf{2}(\mathbf{0 . 5 0} \%)}$ & $\mathbf{T}_{\mathbf{3}(\mathbf{1 . 0 0} \%)}$ & $\mathbf{T}_{\mathbf{4}}(\mathbf{1 . 5 0} \%)$ \\
\hline AST & $33.67 \pm 33$ & $42.33 \pm 1.4$ & $36.33 \pm 5.61$ & $3.00 \pm 9.07$ \\
ALT & $9.07 \pm 83$ & $8.07 \pm 3.34$ & $5.23 \pm 29$ & $9.07 \pm 18$ \\
ALP & $170.67 \pm 3.18$ & $168.67 \pm 88$ & $172.00 \pm 4.16$ & $169.67 \pm 1.20$ \\
T.P & $44.33 \pm 2.33$ & $46.00 \pm 2.52$ & $50.00 \pm 1.53$ & $50.67 \pm 88$ \\
Mg & $24.67 \pm 1.45^{\mathrm{b}}$ & $27.33 \pm 1.45^{\mathrm{ab}}$ & $31.67 \pm 2.03^{\mathrm{a}}$ & $32.33 \pm 1.45^{\mathrm{a}}$ \\
T.B & $8.73 \pm 15$ & $9.40 \pm 10$ & $7.87 \pm 1.04$ & $8.07 \pm 1.44$ \\
L.B & $6.30 \pm 12$ & $6.80 \pm 31$ & $5.43 \pm 35$ & $4.70 \pm 1.27$ \\
Na & $124.33 \pm 5.36$ & $126.67 \pm 2.40$ & $129.00 \pm 2.08$ & $137.33 \pm 6.23$ \\
K & $4.06 \pm 42$ & $4.23 \pm 18$ & $4.30 \pm 15$ & $5.13 \pm 58$ \\
Urea & $1.80 \pm 06^{\mathrm{a}}$ & $1.27 \pm 03^{\mathrm{bc}}$ & $1.03 \pm 02^{\mathrm{c}}$ & $1.51 \pm 19^{\mathrm{ab}}$ \\
\hline
\end{tabular}

$\overline{a, b, c}$ Means in the same row with different superscripts varies significantly $[\mathrm{P}<0.05), \mathrm{AST}=$ Aspatate aminotransferase, $\mathrm{ALT}=$ Alaninaminotarnsferase, $\mathrm{ALP}=$ Alkaline Phosphate, Total Protein, $\mathrm{Mg}=$ Magnesium, $\mathrm{T} . \mathrm{B}=$ Total Blood, L.B.

$=$ Liquid blood, $\mathrm{Na}=$ Sodium, $\mathrm{K}=$ Potassium

\section{Conclusion}

Dietary inclusion of $0.50 \%$ of avocado seed meal in diets of broiler chickens improved weight gain. Also, avocado seed meal had no effect on monitored blood biochemical parameters except for magnesium and urea.

\section{References}

Abeke, F. O. 2005. Evaluation of the nutritive value of Lablab purpureus beans in replacement for groundnut cake in poultry diets. Ph.D Thesis, Ahmadu Bello University, Zaria, Nigeria.

Dabas, D., Shegog, R. M., Zieglier, G. R. and Lambert, J. D. 2013. Avocado (Persea American) seed as a source of Bioactive phytochemicals. Current Pharmaceutical design, Vol 19(3)

Esonu, B. O., Emenalom, O. O., Udedibie, A. B. I., Herbert, U., Ekpor, C. F., Okoli, I. C. and Ihukwumere, F. C. 2001. Performance and blood chemistry of weaner pigs fed raw mucuna beans (velvet bean) meal. Tropical Animal production investment; 4:49-54.

Iyayi, E. A. and Tewe, O. O. 1998. Serum Total protein, urea and creatine levels as indices of quality cassava diets for pigs. Tropical veterinary, 16: 57-67.
Longe, O. G. and Adekoya, O. E. 1988. Response of laying hens to different levels of Palm kernel meal and vegetable oil., Nigerian Journal of Animal Production, 15,1 and 2:111-118.

Sarangi, N. R., Babu, L. K., Kumar, A., Pradhan, C. R., Pati, P. K. and Mishra, J. P. ${ }_{2016 .}$ Effect of dietary supplementation of prebiotic, probiotic, and synbiotic on growth performance and carcass characteristics of broiler chickens. Veterinary World, Vol.9

Nwambe, R. N., Omeje, S. I. and I s i kwe nu, J . O . 2008 . Performance and Economic Analysis of broiler chicks fed Bambara groundnut potash boiled meal as a replacement for soyabean meal at starter phase. Proceeding of Animal Science Association of Nigeria.Pp.294.

Obun, C. O., Kehinde, A. S. and Osaguona, P. O. 2013. Effects of feeding Broiler chicks graded level of sun-cured neem (Azadirachta indica, A. juss) leaf meal on Blood. Greener journal of Agricultural science.

Van Ryssen, J. B. J., Skenjana, A. and Van Niekerk, W.A. 2013. Applied Animal Husbandry 
Performance and biochemical parameters of broiler chickens fed avocado (Persea americana)

Sese, B. T., George, O. S. and Etela, I. 2013. Utilizing Mud Crab ( $U C A$ Tangeri) Meal as a Partial Substitute for Soyabean Meal in Broiler Production. Journal of Environment and Earth Science, Vol. 3, No.4
Whitney, E. and Rolfes, S. R. 2005. Understand Nutrition, 10th Edition, Thomson Wadwoth, Co.19

Received: $20^{\text {th }}$ November, 2019

Accepted: $2^{\text {nd }}$ March, 2020 